Красинский Владислав Вячеславович

доктор юридических наук, полковник, член экспертной группы по международному антиэкстремистскому сотрудничеству при МИД России

Машко Владислав Валерьевич, доцент кафедры москвоведения Российского государственного гуманитарного университета, кандидат исторических наук

Источник опубликования: Красинский В.В., Машко В.В. Проблемные вопросы прогнозирования деятельности международных террористических организаций (на примере деятельности МТО «Исламское государство») // Право и образование. 2016. № 3.

\title{
Проблемные вопросы прогнозирования деятельности международных террористических организаций (на примере международной террористической организации «Исламское государство»)
}

В статье рассматриваются теоретико-методологические подходы к прогнозированию деятельности террористических организаций. Обосновывается значение прогнозной функции в деятельности правоохранительных органов и спецслужб. На примере международной террористической организации «Исламское государство» продемонстрирована методика прогнозирования деятельности террористических структур.

This article analyzes the problem of theoretical and methodological approaches of forecasting terrorist organizations. Substantiates the predictive value of function in the law enforcement and intelligence agencies. Methods of predicting the activities terrorist organizations based on ISIS example.

Ключевые слова: прогноз, прогнозирование, террористическая организация, факторный анализ, международный терроризм, ИГИЛ, «Исламское государство».

Key words: forecast, forecasting, terrorist organization, factor analysis, international terrorism, ISIS, "Islamic State".

Эффективное противодействие международным террористическим организациям (далее - MTO) невозможно без прогнозирования их деятельности, без четкого представления о целях, тактике и возможностях террористов. Наличие прогнозов деятельности МТО позволяет правоохранительным органам и специальным службам пресекать активность террористов на ранней стадии и вовремя принимать необходимые профилактические меры. 
Участие России в антитеррористической операции в Сирии актуализирует вопросы прогнозирования деятельности террористических структур. В связи с этим в настоящее время перед научным сообществом стоит задача адаптации и совершенствования прогнозных методов для анализа деятельности террористических организаций.

Следует отметить, что, несмотря на то, что в зарубежной и отечественной литературе имеется немало работ, посвященных методологии и методике прогнозных исследований $[3,4,6,7,9]$, вопросы прогнозирования деятельности МТО за редким исключением [8] остаются вне поля зрения исследователей. Апробированной методики перспективного изучения МТО в современной террологии не существует.

Рассматривая особенности прогнозирования террористических организаций, следует выделить объективно существующие возможности и границы прогнозирования деятельности МТО. В частности, использование метода экстраполяции во многом ограничено изменчивостью соотношения между решающими и второстепенными факторами, определяющими деятельность террористических организаций.

В случае с МТО мы имеем дело с прогнозированием динамики неустойчивых систем, в связи с этим достоверность прогнозов на среднесрочную и тем более на долгосрочную перспективу является невысокой.

Прогнозирование деятельности террористических организаций можно осуществлять с помощью различных методов: моделирования, экспертных оценок, экстраполяции, построения сценариев и др. Однако учитывая специфику объекта прогнозирования, наиболее детальными и учитывающими различные аспекты функционирования МТО являются прогнозы, в основе которых лежит факторный анализ - изучение закономерностей, выявленных на основе исследования устойчивых количественных и качественных характеристик объекта (факторов). Использование факторного анализа позволяет глубже разобраться в причинах 
изменения исследуемых явлений, оценить место и роль каждого фактора в формировании исследуемых показателей, а также точнее и детальнее экстраполировать выявленные тенденции в будущее [3, С.28].

Можно выделить следующие основные этапы факторного анализа:

1. Постановка чели и задач прогноза.

Целью прогноза, как правило, является анализ угроз, исходящих от MTO, для конкретной страны (региона). В качестве задач можно сформулировать: выделение факторов развития МТО на современном этапе, определение возможных сценариев развития обстановки, исходя из выявленных тенденций и др.

2. Определение факторов, влияющих на исследуемые показатели.

Исследуемые показатели формулируются, исходя из задач прогнозного исследования. Как правило, ими выступают тенденции развития МТО, уровень потенциальной террористической угрозы со стороны данной организации и др.

Отбор факторов, влияющих на исследуемые показатели, осуществляется на основе теоретических и практических знаний в области противодействия терроризму. При этом исходят из принципа: чем больше аспектов функционирования исследуемого объекта проанализировано, тем точнее будут результаты анализа и достовернее прогноз.

При отборе факторов следует учитывать, что одни факторы оказывают воздействие на исследуемые показатели непрерывно, а другие периодически (например, факторы, определяющие стратегию террористической организации, как правило, носят долговременный характер и в той или иной мере постоянно оказывают влияние на ее деятельность, а факторы, обуславливающие организационные связи МТО с другими группировками могут носить временный, периодически проявляющийся характер).

Некоторые факторы по своему составу являются сложными, состоящими из нескольких элементов. Так, фактор наличия в составе 
террористической организации иностранных боевиков в общем виде включает в себя их количество, половозрастные характеристики, гражданство боевиков и т.П.

3. Систематизаџия (группировка) факторов с иелью обеспечения комплексного и системного подхода $к$ исследованию их влияния на исследуемые показатели.

Выявленные факторы могут быть систематизированы по разным признакам. Так, например, исходя из характера их воздействия они могут быть разделены на интенсивные и экстенсивные. К экстенсивным относятся факторы, которые связаны с изменением количественных характеристик функционирования террористической организации (например, динамика численности МТО в связи с пополнением новыми членами, «боевыми» потерями), а интенсивные факторы характеризуют качественную сторону ее функционирования (например, стратегическое планирование террористической деятельности МТО).

4. Определение зависимости между отобранными факторами и исследуемыми показателями:

а) оценка роли каждого фактора и их совокупности (учет перехода количественных изменений в качественные) в изменении исследуемых показателей.

При анализе роли факторов целесообразно определить их иерархию (соподчиненность), выделив факторы первого и второго уровней подчинения (возможно выделение бо́льшего числа уровней). К факторам первого уровня могут быть отнесены те, которые непосредственно влияют на исследуемый показатель (решающие факторы), а к факторам второго уровня - влияющие на него косвенно, в совокупности с другими факторами, или же обусловленные факторами первого уровня.

б) моделирование взаимосвязей факторов между собой, а также между факторными и исследуемыми показателями; 
Необходимо учитывать, что если комплекс факторов рассматривается исключительно как механическая сумма, без учета их взаимодействия, без выделения главных, определяющих, то выводы могут быть ошибочными.

5. Построение возможных сценариев развития ситуащии $u$ определение наиболее вероятного из них (исходя из совокупности рассмотренных факторов и их влияния на исследуемые показатели).

6. Экспертиза и при необходимости доработка прогнозного исследования (для этого могут использоваться экспертные оценки специалистов в области террологии). Экспертиза прогноза снижает субъективизм, неизбежно присутствующий в прогнозных исследованиях.

В качестве примера прогнозирования деятельности террористической организации на среднесрочную перспективу рассмотрим развитие МТО «Исламское государство» (далее - МТО «ИГ).

Целью данного прогноза является исследование комплекса угроз, исходящих от МТО «ИГ», для Российской Федерации, а основными задачами:

- определение основных факторов, определяющих развитие МТО «ИГ» на современном этапе;

- выявление возможностей МТО «ИГ» по переносу террористической деятельности на территорию Российской Федерации;

- построение сценария развития угроз безопасности Российской Федерации, исходящих от МТО «ИГ».

В качестве методологической основы прогнозирования будем использовать факторный анализ.

Выделение значимых факторов, определяющих деятельность МТО «ИГ», целесообразно осуществлять по магистральным тематическим блокам, которые в наибольшей степени поддаются прогнозированию, причем вначале составляется широкий ситуационный список, который по мере сбора информации корректируется и на завершающей стадии включает в себя основные факторы, определяющие развитие МТО «ИГ» (большинство из которых являются сложными по своему составу). 
Группировка факторов по тематическим блокам и выделение сложных факторов необходимы для удобства работы с массивом факторов. При этом возможны различные варианты группировки анализируемых факторов.

На возможности международной террористической организации «Исламское государство» по переносу своей деятельности на территорию Российской Федерации в настоящее время оказывает влияние значительное количество факторов, связанных как с внутренним развитием самой МТО «ИГ», так и с противодействием органов безопасности и правоохранительных органов террористическим устремлениям данной организации, а также с деятельностью третьих стран.

Рассмотрим факторы, определяющие развитие МТО «ИГ» и влияющие на формирование угроз со стороны этой группировки для Российской Федерации, включая потенциальное распространение деятельности МТО непосредственно на российскую территорию:

\section{Внутренние факторы развития МТО «ИГ»:}

- непрекращающееся пополнение группировки опытными боевиками и новобранцами, в том числе мобилизованными (al);

- участие в боевых действиях на стороне МТО «ИГ» на территории Сирии и Ирака более 20 тыс. иностранных «джихадистов», в том числе более 7 тыс. граждан стран СНГ (a2);.

- рост дезертирства из МТО «ИГ» (a3);

- наличие у МТО «ИГ» большого количества оружия, боеприпасов и других материально-технических ресурсов, захваченных в ходе боевых действий в Ираке и Сирии, производящихся собственными силами, а также приобретаемых через посредников из третьих стран (a4);

- сокращение производственных мощностей (по производству оружия, боеприпасов, предприятий нефтедобывающего и нефтеперерабатывающего комплексов и т.п.), подконтрольных МТО «ИГ» на территории Сирии и Ирака (a5); 
- сокращение каналов финансирования МТО «ИГ» $(a 6)$;

- наличие у организации значительных финансовых средств, источники поступления которых диверсифицированы таким образом, что перекрытие одного или нескольких из них не отражается существенным образом на ее деятельности ( $(a 7)$;

- наличие четко выстроенной иерархичной организационной структуры управления боевыми подразделениями, а также эффективная организация системы гражданского управления на подконтрольных группировке территориях (a8);

- значительные потери МТО «ИГ» в живой силе, технике, вооружении и боеприпасах ( $a 9)$;

- присутствие в рядах МТО «ИГ» квалифицированных военных, технических и управленческих кадров как среди высшего руководства, так и на низовых уровнях (a10).

К внешним факторам развития МТО «ИГ» относятся:

- антитеррористическая операция ВКС России, способствовавшая переходу правительственных войск в Сирии в наступление (bl);

- военно-техническая помощь, оказываемая вооруженным силам Сирии Россией, Ираном и ливанской «Хезболлой» $(b 2)$;

- продолжающаяся операция сил международной коалиции под эгидой США по противодействию МТО «ИГ» в Ираке и Сирии (b3);

- материально-техническая, финансовая и иная помощь, негласно оказываемая МТО «ИГ» политическим руководством и частными «спонсорами» Турции, Катара, Саудовской Аравии и ряда других зарубежных государств (b4);

- наличие широких связей с «идеологически близкими» радикальными группировками за пределами Ближневосточного региона, включая некоторые салафитские организации, и использование их 
пособнических сетей для вербовки рекрутов, сбора денежных средств и пропаганды (b5);

- активное создание провинций самопровозглашенного «халифата» на территориях ряда стран Ближнего Востока, Персидского залива, Северной и Западной Африки, а также в афгано-пакистанской зоне, в том числе путем включения в состав МТО «ИГ» региональных «джихадистских» группировок $(b 6)$.

Факторы, влияющие на выработку стратегии и тактики действий МТО «ИГ», представлены:

- наличием долгосрочного стратегического планирования, предусматривающего поэтапное распространение активности группировки сначала в регионе Леванта, а в перспективе - на обширные территории от Западной Африки до Китая и островных государств Азиатско-Тихоокеанского региона (c1);

- приоритетностью на текущем этапе ближневосточного театра военных действий над другими (контроль МТО «ИГ» над частью территорий Сирии и Ирака позволяет ей заявлять о существовании «халифата» и, как следствие, занимать доминирующее положение среди других террористических организаций) (c2);

- экспансионистской стратегией MTO, направленной на включение в орбиту деятельности группировки новых стран и регионов, в том числе Северной Африки, Среднего Востока, Центральной Азии и отдельных районов Афганистана, Китая и др. (c3);

- повышением эффективности (по качественным и количественным показателям) информационно-пропагандистской деятельности МТО «ИГ» в сети «Интернет», ориентированной на привлечение новых сторонников, а также проведением диверсионнотеррористических акций с целью дестабилизации обстановки террористами-одиночками в арабских странах Ближневосточного региона и мусульманских диаспорах в России, государствах Европы и 
Центральной Азии (c4);

- высокой мобильностью сторонников МТО «ИГ», отождествляющих себя не с конкретной этнической группой, а с трансграничной общностью (уммой) мусульман-суннитов (c5);

- использованием эмиссарами МТО «ИГ» членов мусульманских диаспор, проживающих в различных странах мира, для вербовки новых сторонников и организации террористических актов (c6);

- использованием «джихадистами» каналов нелегальной миграции в страны Европейского союза с целью совершения диверсионно-террористических акций, легализации под другими установочными данными и др. (c7);

- высоким уровенем радикализации МТО «ИГ»и оправданием своей террористической деятельности необходимостью защиты «правоверных мусульман» от стран Запада (c8).

Факторы, влияющие на деятельность МТО «ИГ» в отночении Российской Федерации:

- усиление информационно-пропагандистской деятельности МТО «ИГ», в том числе в русскоязычном сегменте сети «Интернет» $(d l)$;

- вхождение России, наряду с США, Ираном и рядом других стран в число прямых врагов «халифата» и объявление МТО «ИГ» Российской Федерации джихада в связи с усилением российской военной поддержки законных сирийских властей и авиаударами ВКС России по объектам группировки в Сирии $(d 2)$;

- присутствие в рядах МТО «ИГ» более 2,5 тыс. граждан Российской Федерации $(d 3)$;

- переход многих действующих в Сирии и Ираке боевиков, связанных с террористической организацией «Имарат Кавказ», в структуры МТО «ИГ» $(d 4)$;

- расширение организационных связей МТО «ИГ» с главарями бандформирований, базирующихся на Северном Кавказе и в Грузии, и 
присоединение значительной части боевиков «Имарата Кавказ» к новому региональному отделению «халифата» МТО «ИГ» - «вилайяту Кавказ» $(d 5)$;

- реализация органами безопасности России эффективного комплекса мер по противодействию МТО «ИГ» на территории Российской Федерации и усиление давления на связанные с ней группировки исламистского бандподполья, действующие на Северном Кавказе (d6). Так, число преступлений террористической направленности на Северном Кавказе в 2015 г. по сравнению с 2014 г. сократилось втрое [2];

- наличие пособнической базы МТО «ИГ» на территории Российской Федерации (свыше 4 тыс. граждан из 77 субъектов Российской Федерации принимали участие в финансировании МТО «ИГ» и т. п. [2]) (d7);

- наличие в исправительных учреждениях Российской Федерации значительного числа заключенных, осужденных за террористическую и экстремистскую деятельность, многие из которых ежегодно выходят на свободу $(d 8)$;

- отсутствие у МТО «ИГ» серьезной поддержки среди населения Северного Кавказа, а также среди российских мусульман в целом (d9). К фактором первого уровня относятся: a1,a2,a7,a8,a10,b1,b2,b3,b4,b5,c1,c2,c3,c4,c8,d2,d3,d6,d7,d8,d9. Именно эти факторы в бо́льшей степени будут оказывать влияние на деятельность МТО «ИГ» в будущем.

Факторы, определяющие развитие террористической организации на современном этапе, взаимосвязаны и влияют друг на друга. Так, например, изменение факторов а3, a5, a6, a9 будет зависеть от динамики факторов b1, b2, b3; факторы a2, c3, d1, d3, d4, d7 взаимосвязаны между собой и т.д. (рамки научной статьи не позволяют привести все схемы влияния факторов друг на друга). 
Анализ совокупности факторов, определяющих деятельность МТО «ИГ» в современных условиях, а также их взаимосвязей позволяет сделать следующие выводы относительно намерений и возможных действий данной террористической организации в отношении России, а также российских граждан и объектов, находящихся за рубежом:

1. Воздействие факторов первого уровня - b1, b2, b3, имеющих положительную динамику, будет и дальше способствовать усилению факторов а3, а5, а6, а9 и ослаблению влияния факторов а4, a8, что приведет к существенному сокращению военного и организационного потенциала МТО «ИГ» и началу постепенного процесса ее трансформации от квазигосударственного образования в «традиционную» террористическую организацию. Однако в кратко- и среднесрочной перспективе полностью ослабить позиции и боевые возможности МТО «ИГ» в Ближневосточном регион не удастся из-за совокупного воздействия ряда факторов (большинство из которых относятся к факторам первого уровня): a 7, a10, b4, b5, b6, c2, с4, с6 и с8.

2. Влияние факторов a2, a9, b1, b2, b3 на деятельность МТО «ИГ» приведет к возвращению в страны происхождения части иностранных боевиков, в том числе российского и центральноазиатского происхождения, многие из которых, тем не менее, (в силу воздействия факторов a8, a10, b4, b5, b6, c1, d7) сохранят связи с руководителями МТО «ИГ» и продолжат экстремистскую и террористическую деятельность.

3. Факторы a2, b1, b6, c1, c3, c8, d2, d3, d5, d7 будут способствовать дальнейшим попыткам направления руководством МТО «ИГ» боевиков российского происхождения на родину для создания там «спящих» ячеек группировки, а также ведения пропагандистской и диверсионнотеррористической деятельности с целью дестабилизации обстановки и подготовки почвы для более масштабного проникновения группировки в эти регионы. 
4. Несмотря на неоднократные заявления руководства МТО «ИГ» о намерении в ближайшее время перенести вооруженную борьбу в страны Европы, Центральной Азии, а в последнее время также угрозы в отместку за «притеснение российскими властями мусульман Чечни», поддержку властей Сирии и авиаудары ВКС России по позициям группировки в Сирии развязать «джихад» на Северном Кавказе и в других южных российских регионах, реализация подобного сценария в обозримом будущем маловероятна (в силу влияния факторов а6, а9, с2, $\mathrm{d} 6$ и $\mathrm{d} 9$ ).

5. В среднесрочной перспективе следует ожидать сохранения тех тенденций, которые определяют развитие обстановки на территории Российской Федерации в настоящее время (обусловлено влиянием факторов первого уровня b1, d6 и d9). Вместе с тем, учитывая, что ряд высокопоставленных командиров и часть наиболее опытных боевиков MTO «ИГ» прибыли с Северного Кавказа (преимущественно из Чечни и Дагестана, а также из Панкисского ущелья на территории Грузии), можно ожидать дальнейшего укрепления организационных связей этой группировки с «идеологически родственными» ей структурами исламистского бандподполья в южных российских регионах, а также на территориях соседних государств (воздействие факторов а2, b5, c3, с4, c5, d4, d5 и d7). Таким образом, долгосрочные угрозы национальной безопасности Российской Федерации, связанные с деятельностью МТО «ИГ», сохранятся.

6. В ближайшее время поток возвращающихся в Россию боевиков МТО «ИГ» может превысить число экстремистов, выезжающих за рубеж для ведения джихада (влияние факторов а3, a5, a6, a9, b1, b2 и b3). Возвращение в Российскую Федерацию лиц, принимавших участие в вооруженном конфликте в Сирии и Ираке, может привести к радикализации исламского сообщества в России (особенно среди 
молодежи), однако серьезное увеличение численности «джихадистов» среди российских мусульман маловероятно в силу факторов d6 и d9.

7. С учетом продолжающегося роста популярности МТО «ИГ» на Ближнем Востоке, в Северной и Центральной Африке и других регионах (воздействие факторов b5, c1, c3, c4, c5, c6 и d1) ожидается увеличение числа радикальных группировок, присягнувших на верность этой организации в разных странах мира. В связи с этим значительно возрастает опасность для российских граждан, дипломатических представительств и других объектов России за рубежом подвергнуться нападению или стать жертвами терактов.

8. Наличие относительно устойчивых по своей динамике факторов а2, $\mathrm{c} 5, \mathrm{c} 7, \mathrm{c} 8$ и $\mathrm{d} 2$ при усиливающемся или устойчивом воздействии факторов $\mathrm{d} 6$ и d9 приведет к росту вероятности использования МТО «ИГ» так называемой тактики «косвенных ударов», то есть организации террористических актов, которые в целях дезинформации правоохранительных органов и спецслужб будут осуществляться не гражданами России, а иностранцами. В связи с этим возможно проникновение боевиков МТО «ИГ» на территорию Российской Федерации через государства Центральной Азии, в том числе с использованием каналов трудовой миграции.

9. Наличие факторов d1 и d8 свидетельствует, что потенциальным ресурсом для пополнения рядов боевиков МТО «ИГ» будут выступать граждане, отбывающие наказание за совершение преступлений экстремистского и террористического характера, в том числе уже осужденные за участие в боевых действиях на территории Сирии.

Исходя из выявленных тенденций в развитии МТО «ИГ» можно оценить вероятность сценариев угроз безопасности Российской Федерации, исходящих от деятельности данной террористической организации.

Возможные варианты развития ситуации можно представить в виде трех обобщенных сценариев: благоприятного, относительно благоприятного, неблагоприятного. 
Согласно благоприятному сценарию участие российских воздушнокосмических сил в нанесении авиаударов по позициям МТО «ИГ» в Сирии и действия правительственных войск на суше, а также деятельность сил международной коалиции позволят нанести существенный урон организационным и материально-техническим возможностям МТО «ИГ», что позволит освободить территории, находящиеся в настоящее время под контролем данной террористической организации. Деятельность правоохранительных органов и спецслужб минимизирует негативные последствия возвращения граждан Российской Федерации, принимавших участие в боевых действиях на стороне МТО «ИГ», на родину.

Согласно относительно благоприятному сиенарию организационным и материально-техническим возможностям МТО «ИГ» будет нанесен значительный урон, однако полностью ослабить позиции террористической организации в Ближневосточном регионе не удастся. Следствием развития ситуации по данному сценарию станет сохранение тех тенденций, которые определяют развитие обстановки на территории Российской Федерации в настоящее время. При этом организационные связи МТО «ИГ» с бандподпольем на территории Северного Кавказа останутся неустойчивыми.

Согласно неблагоприятному сценарию участие российских Воздушно-космических сил в нанесении авиаударов по позициям МТО «ИГ» в Сирии и действия правительственных войск на суше не позволят нанести существенный урон данной террористической организации в Ближневосточном регионе, а активная, наступательная стратегия боевиков позволят им упрочить доминирующее положение в других частях исламского мира. При этом дальнейшее участие Российской Федерации в антитеррористической операции в Сирии приведет к усилению террористических устремлений МТО «ИГ» на российском направлении.

Проведенный факторный анализ позволяет сделать вывод о том, что выявленные тенденции в наибольшей степени соответствуют второму сценарию - относительно благоприятному. 


\section{СПИСОК ЛИТЕРАТУРЫ}

1. Бородин А.М. Терроризм в России: история и современность // Право и образование. 2001. № 3. С.112-131.

2. Глава ФСБ: в Москве. Были задержаны 12 сторонников ИГ, готовивших теракт [Электронный ресурс] Режим доступа: http://tass.ru/politika/2343071 Дата обращения 23.10.2015.

3. Долгосрочное прогнозирование сценариев развития военно-политической обстановки: аналитический доклад / Подберезкин А.И., Мунтян М.А., Харкевич М.В. М.: МГИМО, 2014. 161 с.

4. Долныкова Р.Н. Закономерности и реалии: методология и методика прогнозирования внешней политики. Иерусалим: «Филобиблон», 2008. 499 с.

5. Попов В.И. Терроризм в России: детерминанты и профилактика // Право и образование. 2008. № 9. С.75-82.

6. Попова О.В. Политический анализ и прогнозирование. Аспект Пресс, 2011. $464 \mathrm{c}$.

7. Brown, Timothy A. Confirmatory factor analysis for applied research. Guilford Press, 2006.

8. Edwin Bakker. Forecasting Terrorism the Need for More Systematic Approach // Journal of Strategic Security. Vol. 5. No 4. 2012. P.69-84.

9. Richardson Sue, Tan Yan. Forecasting future demands: what we can and cannot know. Proceeding of National Institute of Labour Studies, Flinder Uneversity. 2005. 43 p. 